American J. of Engineering and Applied Sciences 3 (1): 186-188, 2010

ISSN 1941-7020

(C) 2010 Science Publications

\title{
A Study of Sugarcane Leaf-Removal Machinery during Harvest
}

\author{
Sopa Cansee \\ Department of Mechanical Engineering, Faculty of Engineering, \\ Mahasarakham University, Kamriang, Kantharawichai, Mahasarakham 44150, Thailand
}

\begin{abstract}
Problem statement: Sugarcane leaf-removing tools could help speed up sugarcane harvest and reduce contamination. Moreover, leaf-removal machinery can solve the problems of sugarcane burning and workers can increase sugarcane harvest production too. The purpose of this research was to study the use of leaf-removal machinery in the post-harvest production of sugarcane to reduce harvest production time and contaminant. Approach: This study focused on the LK92-11 variety of sugarcane having a harvesting period of 12 months, a density of 9,387 stems/rai and could produce 14.01 tons/rai including cane top and, leaves and leaf sheaths of 1675.2 and $180 \mathrm{~kg} / \mathrm{rai}$. Sugarcane leafremoval machinery was applied to a small engine power from a grass-cutting machine. A rotate dish applied 4 different materials, tendon string, soft wire, medium wire and sling for sugarcane leafremoving. The machine was operated at a constant speed. The efficiency of the sugarcane leaf-removal machinery indicated the capacity of sugarcane leaf-removing by area and operation time. Results: The quantity of leaves and leaf sheaths affect the speed of harvest production. Moreover, leaves and leaf sheaths increase the waste material in production and also contaminate the sugar and the sugar production system with clay, sand, and mud from the fields. Traditional methods for sugarcane harvest without removing leaf took $37 \mathrm{~h}$ /rai to complete, but sugarcane leaf-removing could reduce the sugarcane harvest process to $11.4 \mathrm{~h} / \mathrm{rai}$. Conclusion: The material of the blades in de-leafing machine is crucial to the efficiency of harvest production time. Blades made from poor materials can cause tangling and clogging in the rotator dish, which increases maintenance time. Further developments in sugarcane leaf removal systems will create dramatic improvement in sugarcane production.
\end{abstract}

Key words: Sugarcane harvest, Leaf and leaf sheath, Leaf-removal machinery

\section{INTRODUCTION}

Sugarcane is an important economic crop of farming in Thailand. Thailand has cultivating area of 6.31 million rais producing sugarcane stem of 64.37 million tons and sugar of 7.60 million tons annually (The Office of Sugarcane and Sugar Commission, 2008). Thailand exported more sugar to foreign markets between 2002 and 2007, that was, 1.97 million tons and valued 16,448.69 million Baht, and 2.03 million tons and valued 21,807.27 million Baht, respectively (The Office of Agriculture Economy, 2008). In addition, Sugarcane can be used to produce renewable energy which is an urgent plan of economic development on government policy.

Sugarcane harvesting is a critical step that must be managed to maintain good quality and quantity of sugarcane production. Farmers harvesting sugarcane have a leaves-removing step and cut the stem closing to the soil, then cut the top of sugarcane stem. Leaves and leaf sheaths of sugarcane caused delay of harvesting. Moreover, the sugarcane crop that has not been fully leaves-removed could carry some soil, sand and mud, thus damaging the downstream sugarcane process machine and reduced sugar yield (Yangyeun and Wongpicheth, 2008). Tinnangwattana (2008) reported that there was contamination of the sugarcane from workers carrying four types of sugarcanes: fresh sugarcane, sugarcane with its top uncut, sugarcane fire and sugarcane un-cut the top fire were contaminated of $5.77,12.58,7.81$ and $13.31 \%$ by weight, respectively. The contamination will be increased more than this when using the car to grip sugarcane to the truck. Farmers who have workerless cannot do sugarcane harvesting during factory operation time. They burn sugarcane in order to eliminate the leaves to speed up the sugarcane harvesting. The sugarcane fire had disadvantages such as weight reduction, pathogens destroyed easily, rapid decrease of sweetness, high production cost of plant, that organic material and structure in soil were destroyed and decreased sugar production.

Sugarcane leaf-removing tools could help speed up sugarcane harvest and reduce contamination. However, 
researchers in the past had focused on tools or equipments used to help harvest sugarcane crop; for example, sugarcane harvester, knife used for sugarcane crop on performance to sugarcane harvester.

However, leaf-removal machinery can solve the problems of sugarcane burning and reduce contaminants. Moreover, workers can increase sugarcane harvest production too.

\section{MATERIALS AND METHODS}

The study into sugarcane leaf-removal machinery during harvest process aimed at studying the situations of harvesting sugarcane of farmers and at using sugarcane leaf-removal machinery. The LK92-11 variety of sugarcane having a harvesting period of 12 months was used as sample, Ban Phai, Khon Kaen province, Thailand.

Sugarcane harvest field, Fig. 1 shows length between plant spots of gross sugarcane in the field. Density of sugarcane plant is the ratio of sugarcane stem to area. The quantity of sugarcane production can be weighed by randoming sugarcane stem which was cut on part of the cane top and leaf was removed.

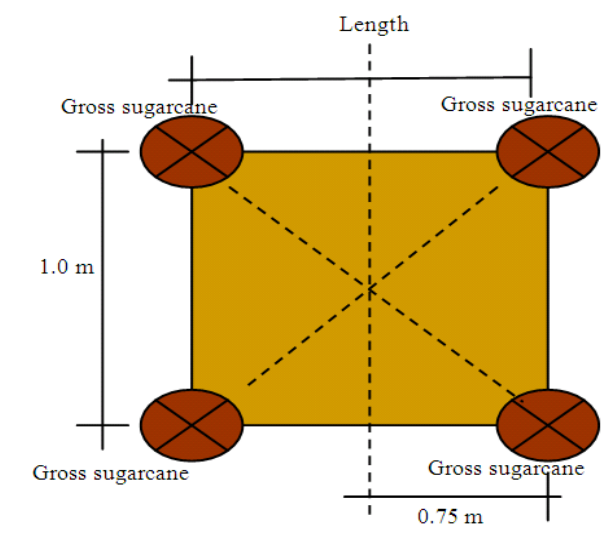

Fig. 1: Length of plant gross sugarcane

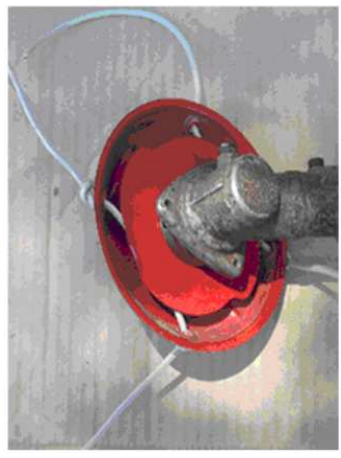

Fig. 2: A soft wire on rotate dish
Moreover, the cane top of stem and leaf removing were weighed too. The density of sugarcane and its leaves affects the time of harvest. Therefore, we compared the time of sugarcane harvesting by workers during leaves removing and leaves not removed too.

Experimental testing, Sugarcane leaf-removal machinery was applied to a small engine power from a grass-cutting machine. A rotate dish applied 4 different materials, tendon string, soft wire, medium wire and sling for sugarcane leaf-removing as shown in Fig. 2. The machine was operated at a constant speed. The efficiency of the sugarcane leaf-removal machinery indicated the capacity of sugarcane leaf-removing by area and operation time.

\section{RESULTS AND DISCUSSION}

The LK92-11 variety of sugarcane having a harvesting period of 12 months had density of 9,387 stems/rai $\left(1600 \mathrm{~m}^{2}\right)$, corresponding to sugarcane production that removes the cane top and reveal leaves of 12.16 tons/rai (Table 1). The sugarcane size per stalk was $2.87 \mathrm{~cm}$ of bottom diameter by average, $2.08 \mathrm{~m}$ of length and $1.295 \mathrm{~kg}$ of weight.

Table 2 shows weight of cane top which is sweetless, $178.5 \mathrm{~g} / \mathrm{stalk}$. The quantities of cane top by multiple with the density are $1,675.52 \mathrm{~kg} / \mathrm{rai}$, whereas the quantities of sugarcane leaves and leaf sheaths are $180 \mathrm{~kg} / \mathrm{rai}$ at moisture content of $49.63 \% \mathrm{wb}$.

Table 1: Size of harvest sugarcane crop

\begin{tabular}{|c|c|c|c|}
\hline \multirow[b]{2}{*}{ Rep. } & \multicolumn{3}{|c|}{ Sugarcane size per stem } \\
\hline & $\begin{array}{l}\text { Bottom diameter } \\
(\mathrm{cm})\end{array}$ & $\begin{array}{l}\text { Sugarcane length } \\
\text { (m) }\end{array}$ & $\begin{array}{l}\text { Weight } \\
(\mathrm{kg})\end{array}$ \\
\hline$\overline{1}$ & 2.80 & 2.49 & 2.200 \\
\hline 2 & 2.60 & 1.98 & 1.100 \\
\hline 3 & 2.90 & 2.00 & 1.270 \\
\hline 4 & 3.20 & 1.98 & 1.300 \\
\hline 5 & 2.60 & 1.73 & 0.870 \\
\hline 6 & 3.00 & 2.20 & 1.480 \\
\hline 7 & 3.00 & 2.16 & 1.290 \\
\hline 8 & 3.20 & 2.21 & 1.430 \\
\hline 9 & 3.00 & 2.07 & 1.210 \\
\hline 10 & 2.40 & 1.95 & 0.800 \\
\hline Average & 2.87 & 2.08 & 1.295 \\
\hline \multicolumn{4}{|c|}{ Table 2: Weight of the cane top } \\
\hline \multicolumn{2}{|l|}{ Rep. } & & Weight $(\mathrm{g})$ \\
\hline \multicolumn{2}{|l|}{$\overline{1}$} & & 2000.0 \\
\hline \multicolumn{2}{|l|}{2} & & 1950.0 \\
\hline \multicolumn{2}{|l|}{3} & & 2200.0 \\
\hline \multicolumn{2}{|l|}{4} & & 2250.0 \\
\hline \multicolumn{2}{|l|}{5} & & 1500.0 \\
\hline \multicolumn{2}{|l|}{6} & & 1700.0 \\
\hline \multicolumn{2}{|l|}{7} & & 1900.0 \\
\hline \multicolumn{2}{|l|}{8} & & 1100.0 \\
\hline \multicolumn{2}{|l|}{9} & & 1950.0 \\
\hline \multicolumn{2}{|l|}{10} & & 1300.0 \\
\hline \multicolumn{2}{|l|}{ Average } & & 178.5 \\
\hline
\end{tabular}


Am. J. Engg. \& Applied Sci., 3 (1): 186-188, 2010

Table 3: Comparison of sugarcane harvest time per bundle between sugarcane leaf removing and sugarcane leaf non-removing

Leaves removing Leaves un-removing

\begin{tabular}{lclcl} 
No. & Stalk bundle $^{-1}$ & Time $(\mathrm{min})$ & Stalk bundle $^{-1}$ & Time $(\mathrm{min})$ \\
\hline 1 & 8.00 & 2.08 & 11.00 & 2.36 \\
2 & 14.00 & 1.28 & 8.00 & 2.17 \\
3 & 11.00 & 2.01 & 12.00 & 2.11 \\
4 & 10.00 & 2.09 & 9.00 & 2.45 \\
5 & 12.00 & 2.31 & 14.00 & 3.34 \\
6 & 11.00 & 1.10 & 9.00 & 2.57 \\
7 & 9.00 & 1.11 & 12.00 & 2.49 \\
8 & 8.00 & 1.10 & 13.00 & 3.02 \\
9 & 12.00 & 2.44 & 8.00 & 2.20 \\
Average & 10.56 & 1.72 & 10.67 & 2.52
\end{tabular}

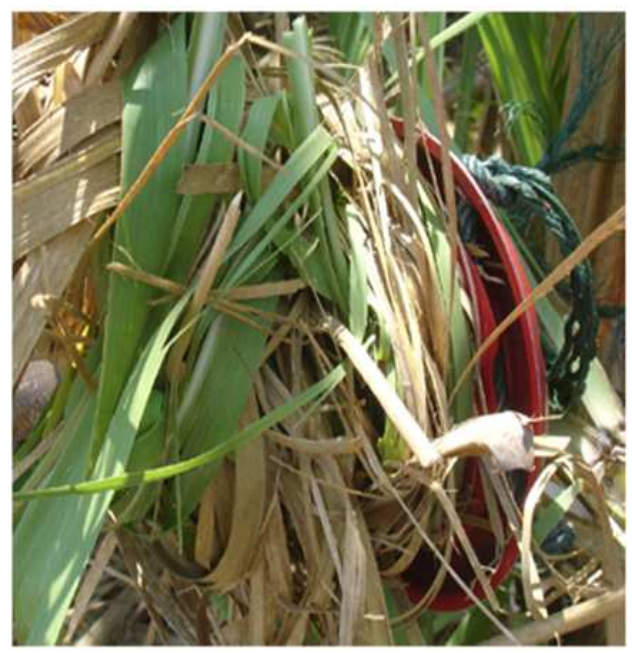

Fig. 3: The sugarcane leaves get stuck with rotate dish

The quantities of cane tops, leaves and leaf sheaths affect harvesting management process. Table 3 shows comparison of sugarcane harvest time per bundle during leaves removing and leaves not removed. The sugarcane harvest of leaves removing took 1.72 $\mathrm{min} /$ bundle whereas leave not removed took 2.52 $\mathrm{min} /$ bundle. Therefore, if conversion time of sugarcane harvest is per rai, the sugarcane not removed leaves took time of $37.0 \mathrm{~h} / \mathrm{rai}$, and more than removed leaves of 11.4 hours. Moreover, leaves and leaf sheaths are carry soil, sand and mud into sugar production process.

The study of sugarcane leaf-removing machine was applied to a small engine to be the origin power and rotate dish for sugarcane leaf removing from 4 varieties of materials such as tendon string, soft wire, medium soft wire and sling. When testing sugarcane leaves removing, it was found that it could work at a few minutes of operation.

Then, the sugarcane leaves would get stuck with rotate dish (Fig. 3) and was stopped in order to solving problem from time to time. So it would be inconvenient on working. Besides, the high rotating speed will make the material used fixed to the sugarcane stem and easy to damage. Further developments in sugarcane leaf removal systems will create dramatic improvement in sugarcane production.

\section{CONCLUSION}

The LK92-11 variety of sugarcane having harvesting period of 12 months had density of 9387 stems/rai and the production 12.16 tons/rai. The cane top quantity was $1675.52 \mathrm{kgs} / \mathrm{rai}$ by average, the leaves and leaf sheaths of $180 \mathrm{kgs} / \mathrm{rai}$. The quantity of sugarcane leaves and leaf sheaths affected the sugarcane harvesting time. The farmer harvesting sugarcane spent about 37 hours/rai to complete at sugarcane leaves not removed. It took more time for sugarcane leave-removing about 11.4 hours. Besides, leaves and sugarcane leaf sheaths increased the sticking of clay, sand and mud in the field into the sugar production system also. The material of the blades in de-leafing machine is crucial to the efficiency of harvest production time. Blades made from poor materials can cause tangling and clogging in the rotator dish, which increases maintenance time. Further developments in sugarcane leaf removal systems will create dramatic improvement in sugarcane production.

\section{ACKNOWLEDGEMENT}

The authors would like to express their sincere thanks to the Bio-Energy Research Laboratory. Financial support from Faculty of Engineering, MSU, under the incoming budget of the fiscal year 2009 is also gratefully acknowledged.

\section{REFERENCES}

Supan Yangyeun and Seri Wongpicheth, 2008. The study and development of soil and sand separation machine. Harvest Technol. Innovat. Center, 6: 2-4.

Thawat Tinnangwattana, 2008. Modern sugarcane farm harvest and transportation.

http://www.ocsb.go.th/udon/All\%20text/1.Article/0 1-Article\%20P9.1.htm

The Office of Sugarcane and Sugar Commission, 2008. The report on sugarcane and sugar production. http://www.ocsb.go.th/show_list.asp?id=13

The Office of Agriculture Economy, 2008. Monthly export for sugar in quantity and value. http://www.oae.go.th/oae_website/oae_imex.php 